\title{
Research on the Development of China's Manufacturing Industry: Endogenous Innovation and Threshold Effects
}

\author{
Jianjun Sun ${ }^{1, *}$, Shuxiang Wang ${ }^{1}$ and Fang Yuan ${ }^{2}$ \\ ${ }^{1}$ School of Economics and Management, Beijing Jiaotong University, No.3, Shangyuancun Haidian District, Beijing, \\ 100044, China \\ ${ }^{2}$ Business School, University of International Business Economics, No.10, Huixin Dongjie, Chaoyang District, \\ Beijing, 100029, China \\ *Corresponding author. Email: 19113071@bjtu.edu.cn
}

\begin{abstract}
The Chinese manufacturing industry currently faces unprecedented opportunities and challenges related to its development. The choice of an appropriate development approach not only affects the upgrading of the manufacturing industry itself, but also influences the restructuring and evolution of the Chinese economy. First, this article empirically examines manufacturing companies listed in China from 2010 to 2018; an analysis of the relationships between endogenous innovation and manufacturing firms reveals that initially. Second, firms' innovation investments create threshold effects on their development. Finally, the research results indicate that endogenous innovation positively affects manufacturing firms' development showing a U-shape. And, there are threshold effects of endogenous innovation.
\end{abstract}

Keywords: Endogenous innovation, Manufacturing industry, Threshold effects.

\section{INTRODUCTION}

According to the 'Made in China 2025' initiative, China's State Council highlights the significance of improving the manufacturing industry's innovation capacity, which is perceived as the primary task in building a strong manufacturing state. However, China does not exhibit the same manufacturing power as western countries; many sophisticated products, such as smartphone chips, still rely on substantial quantities of imports. The overall R\&D and production levels in China's manufacturing industry still lag behind western manufacturing. Firms under pressure from a challenging and changing external environment should also gain the ability to build and reconfigure their internal and external resources [1]. Therefore, China's manufacturing industry should autonomously explore a development-based approach to adapt to changes and challenges, whether domestic or foreign.

The remainder of this paper is arranged as follows: Section 2 presents a literature review to analyse relevant content and theories regarding the government's guidance and firms' endogenous innovation. Section 3 presents the hypotheses and introduces the model, which is primarily based on firms' endogenous innovation and its threshold effects. Section 4 analyses the empirical results of the model and hypotheses. Section 5 concludes the research.

\section{LITERATURE REVIEW}

Endogenous innovation in particular may be the ideal solution for issues when firms encounter development bottlenecks. March observed that innovation activities can be divided into two types: exploratory and exploitative innovation [2]. Exploitative innovation could more efficiently and effectively provide firms with considerable short-term economic benefits than exploratory innovation. However, firms' long-term development would be hindered by an overreliance on exploitative innovation. Therefore, it should be noted that exploratory innovation could supply firms with long-term, sustainable development power. According to Lee and Malerba's perspective, opportunities, strategies and innovation systems are easily interpreted as indispensable elements for firms in 
technology-developing countries to achieve transcendent development [3]. Using the automotive industry as an example, Kim found through a survey of followers' technology development and innovation activities that firms initially acted mainly as imitators, copying and improving technology from developed countries, and then building their own technology and innovation capabilities step by step [4].

Current theoretical and academic studies on the manufacturing industry's development may primarily focus on firms' technological innovation with regarding with the selection and application of strategies in terms of exploratory and exploitative innovation. This paper differs from prior works to not only focus on the Ushape of endogenous innovation on manufacturing firms' development but also on the endogenous innovation's threshold effects, which means it would take a period of time for endogenous innovation to fully influence on the manufacturing firms' development.

\section{HYPOTHESIS AND MODEL}

\subsection{The influence of Endogenous Innovation on Manufacturing Firms' Development}

Scientific and technological innovation has been significant in promoting China's economic growth. A successful, innovative firm should exhibit strong capabilities in terms of its $R \& D$ strength, marketing ability, and consumer satisfaction. One important motivator for these firms in coping with uncertain internal and external environments involves the active implementation of innovation strategies [5]. In addition to maintaining continuous $\mathrm{R} \& \mathrm{D}$ investments, a company should expand its innovation to outside the firm and its industry. With this type of inclusive attitude, these firms can absorb all resources to promote endogenous innovation activities [6].

According to Nonaka's 'knowledge spiral' theory, knowledge is a key element for innovation as well as a source of innovation, and thus, firms should strive to constantly innovate [7]. According to the 'ambidextrous innovation' theory, exploratory or incremental innovation can improve firms' existing products, techniques and technologies, among other aspects. This latter theory focuses on tracking the trajectories of industrial technology and discovering innovative technical knowledge. Hence, exploratory innovation should be considered the most important innovation strategy. Through experimentation, companies can verify the viability of their innovations, identify problems, and make improvements to their ideas [8]. Unlike exploitative innovation, which is primarily imported or imitated, conducting endogenous innovation is usually a process of trial and error, which is constant upgrading.
H1a: Endogenous innovation positively affects manufacturing firms' development showing a U-shape.

H1b: There are threshold effects of endogenous innovation.

\subsection{The Variables and Model}

As noted in Table 1, this paper's data is mainly based on the CSMAR database, with dates ranging from 2010 to 2018 applied from Chinese-listed manufacturing companies' annual reports. We then eliminated the following: (1) firms that substantially lacked main index data; (2) firms with abnormal business conditions during the study period (e.g. ST versus ST*, among others). The STATA 15 application was used to derive 592 firms for the final analysis.

\subsubsection{Dependent Variable}

Table 1 indicates that the Tobin's Q ratio is applied as a dependent variable to measure firms' levels of development, as this is the ratio between the market value of capital and its replacement cost, which is an important indicator of firms' growth. Additionally, the higher the Tobin's Q ratio, the better the firm's growth, and this ratio is not likely to be manipulated.

\subsubsection{Independent Variables}

As can be observed in this paper in general, and in Table 1 in particular, this paper provides a better analysis of the efficiency of firms' R\&D expenditures by selecting manufacturing firms' internal $R \& D$ expenditure rates as a second explanatory variable. This will measure the impact of endogenous innovation on firms' development.

\subsubsection{Control Variables}

Firms' development may be influenced by factors other than government guidance and endogenous innovation. Studies by Ashbaughskaife et al. and Stoel and Muhanna reveal many other control variables, including companies' size, revenue growth rate, assetliability ratio and age $[9,10]$.

\subsubsection{Model}

According to the threshold regression theory proposed by Hansen [11], $E I_{i, t}$ is threshold variable, $\tau$ is the threshold value and $I(\cdot)$ is the indicator function, and the model is equivalent to a segmented function model where the coefficient of Sit is $\gamma 1\left(E I_{i, t} \leq \tau\right)$ and $\gamma 2$ ( $E I_{i, t}>\tau$ ).

H1a: $T Q_{i, t}=\beta_{0}+\beta_{1} E I_{i, t}+\beta_{2} E I_{i, t}^{2}+\beta_{i}$ Controls $_{i, t}+\varepsilon_{i, t}$

H1b: $T Q_{i, t}=\beta_{0}+\gamma_{1} S_{i, t} I\left(E I_{i, t} \leq \tau\right)+\gamma_{2} S_{i, t} I\left(E I_{i, t}>\right.$

$\tau)+\beta_{i}$ Controls $_{i, t}+\varepsilon_{i, t}$ 


\section{EMPIRICAL RESULTS AND ANALYSIS}

\subsection{Descriptive Statistics}

Table 2 displays the major variables' descriptive statistics. Although some listed manufacturing firms did not receive government subsidies in some years, endogenous innovation $(R I)$ simultaneously exhibits an average of 0.03 , with a maximum of 0.8 , minimum of 0 and 1516 RI amounts observed.
This table also indicates that not all listed manufacturing firms have invested in $R \& D$ expenditures, and some have zero R\&D expenditures in many years. However, many of these firms still spent $80 \%$ of their revenues on $\mathrm{R} \& \mathrm{D}$, as the maximum $E I$ is 0.8. Consequently, manufacturing firms may express different attitudes towards their internal R\&D expenditures. For example, some firms still choose exploitative innovation, and thus, they may directly purchase technology to gain a competitive advantage and rapidly develop.

Table 1. Variable definition and measurement

\begin{tabular}{|c|c|c|c|}
\hline Variable & Name & Symbol & Measurement \\
\hline $\begin{array}{l}\text { Dependent } \\
\text { variable }\end{array}$ & Tobin's Q ratio & $T Q$ & $\begin{array}{c}\text { Tobin's Q ratio = Market value } / \text { Total ending assets; } \\
\text { Market value = Market capitalisation value + Net debt } \\
\text { market value }\end{array}$ \\
\hline $\begin{array}{c}\text { Independent } \\
\text { variable }\end{array}$ & Endogenous innovation & $E I$ & R\&D / Revenue \\
\hline \multirow{5}{*}{ Control variables } & Companies' size & $S$ & The natural logarithm of total ending assets \\
\hline & Revenue growth rate & $R$ & (Revenue - Prior year's revenue) / Prior year's revenue \\
\hline & Asset-liability ratio & $L$ & Total ending assets / Total ending liabilities \\
\hline & The nature of companies & $N$ & $\begin{array}{c}\text { State-owned companies }=1 ; \\
\text { Non-state-owned companies }=0\end{array}$ \\
\hline & Companies' age & Age & Year of observation - Year of IPO \\
\hline
\end{tabular}

Table 2. Major variables' descriptive statistics

\begin{tabular}{|c|c|c|c|c|c|c|}
\hline Var. & Obs. & Mean & S.D. & Min. & P50 & Max. \\
\hline$T Q$ & 5328 & 2.35 & 1.66 & 0.22 & 1.84 & 22.32 \\
\hline$E I$ & 1516 & 0.03 & 0.04 & 0.00 & 0.01 & 0.80 \\
\hline$S$ & 5328 & 22.36 & 1.24 & 18.16 & 22.23 & 27.39 \\
\hline$R$ & 5120 & 0.26 & 0.79 & -0.76 & 0.09 & 5.53 \\
\hline$L$ & 5328 & 0.47 & 0.20 & 0.01 & 0.47 & 2.99 \\
\hline$N$ & 5328 & 0.56 & 0.50 & 0.00 & 1.00 & 1.00 \\
\hline Age & 5328 & 13.96 & 5.57 & 2.00 & 14.00 & 33.00 \\
\hline
\end{tabular}

Table 3. Variable correlation analysis

\begin{tabular}{|c|c|c|c|c|c|c|c|}
\hline Variables & $\boldsymbol{T} \boldsymbol{E}$ & $\boldsymbol{E I}$ & $\boldsymbol{S}$ & $\boldsymbol{R}$ & $\boldsymbol{L}$ & $\boldsymbol{N}$ & $\boldsymbol{A g} \boldsymbol{e}$ \\
\hline$T Q$ & & $0.111^{* * *}$ & $-0.550^{* * *}$ & 0.012 & $-0.481^{* * *}$ & $-0.236^{* * *}$ & $-0.251 * * *$ \\
\hline$E I$ & $0.122 * * *$ & & $-0.105 * * *$ & $0.059 * *$ & $-0.172 * * *$ & $-0.071 * * *$ & $-0.147 * * *$ \\
\hline$S$ & $-0.469 * * *$ & $-0.054 * *$ & & $0.053 * *$ & $0.493 * * *$ & $0.254 * * *$ & $0.354 * * *$ \\
\hline$R$ & $0.049 * * *$ & $0.076 * * *$ & $-0.024 *$ & & $0.061 * *$ & $0.087 * * *$ & -0.014 \\
\hline$L$ & $-0.323 * * *$ & $-0.129 * * *$ & $0.371 * * *$ & 0.007 & & $0.202 * * *$ & $0.140 * * *$ \\
\hline$N$ & $-0.147 * * *$ & $-0.049 *$ & $0.213 * * *$ & $0.030 * *$ & $0.176 * * *$ & & $0.298^{* * *}$ \\
\hline$A g e$ & $-0.131 * * *$ & $-0.128 * * *$ & $0.257 * * *$ & $0.044 * * *$ & $0.101 * * *$ & $0.272 * * *$ & \\
\hline
\end{tabular}

Note: Lower-triangular cells report Pearson's correlation coefficients, while upper-triangular cells indicate Spearman's rank correlations. 


\subsection{Correlation Coefficient Analysis}

Table 3 reports the results from this study's correlation analysis of the model's variables. The correlation coefficient results of $E I$ and $T Q$ are significant at the $1 \%$ level. Simultaneously, this study also discovers that the correlation coefficient among each control variable and $T Q$ is significant at the $1 \%$ level, indicating that the selection of control variables could be representative to a certain extent. Additionally, the absolute value of the control variables' correlation coefficients has a maximum of $0.49(<0.5)$, while the variables' variance inflation factor has a maximum of 1.19 (< 2.5), revealing no serious multicollinearity issue.

\subsection{The Regression Results}

\subsubsection{Endogenous Innovation and Manufacturing Firms' Development}

Possible endogeneity issues in the regression model are avoided by also investigating the influence of independent variable $E I$ on $T Q$ in future periods one and two. The regression data presented in Table 4 indicates that $E I$ and $E I^{2}$ positively correlate with the dependent variable $T Q$, and are significant at the $10 \%$ and $1 \%$ level. Hence, Hypothesis 1a is accepted.

This leads to the conclusion that endogenous innovation positively impacts manufacturing firms' development showing a U-shape. Furthermore, the effect of R\&D expenditure rate, as determined by the endogenous innovation variable, may have a hysteresis effect on firm development. The dependent variable $E I$ is lagged for one and two periods individually to further test and analyze this supposition; the independent variable $E I$ is again used in a data regression. The postlag results, as noted in Table 4, demonstrate that $E I$ is significantly and positively affected at the $10 \%$ level after the first lag. Moreover, it can be observed that it further improves after the second lag, with significant, positive effects at the $1 \%$ level. Therefore, endogenous innovation may positively influence firms' development in the base period. Additionally, this impact would gradually increase in the subsequent two-year period. This may further indicate that it should be difficult for manufacturing firms to gain short-term benefits from
R\&D expenditures; furthermore, it might take many years to promote such firms' development.

\subsubsection{Threshold Effects of Endogenous Innovation}

We set up 200 grid search points and perform 400 bootstrap test replications, starting with; a threethreshold test is performed on the model. Then, in the presence of a threshold effect, the threshold level for each threshold is further estimated, and finally the threshold regression is reported as the parameter estimation. It can be noticed from Table 5 and Table 6, there are single threshold $(\mathrm{p}=0.0775<0.10)$ and double threshold $(\mathrm{p}=0.01<0.05)$ effects at the $10 \%$ and $5 \%$ level without triple threshold effects $(\mathrm{p}=0.225>0.10)$. Hence, Hypothesis $1 \mathrm{~b}$ is accepted. Plus, the first threshold of $E I$ is 0.0344 between 0.0303 and 0.0388 , and the second threshold of $E I$ is 0.0241 between 0.0216 and 0.0267 . It seems that if the manufacturing industry relies on endogenous innovation for sustained growth, the rate of R\&D expenditure needs to exceed to $2.16 \%$ at least and preferably more than $3.44 \%$ for a long time.

\section{CONCLUSION}

This study considers the firm management perspective in empirically examining manufacturing companies listed in China from 2010 to 2018. The relationships between endogenous innovation and firm development were tested, with the following results: First, as a driving force for manufacturing firms, endogenous innovation should ensure these firms' longterm development. Second, although it may take many years for R\&D investments to promote manufacturing firms' development above a certain level of R\&D expenditure rate, these firms' positive innovation strategies may increase market investors' confidence in the industry's future development and stimulate increasing stock prices. What's more, future research should further focus on the invisible innovation elements of endogenous innovation, such as innovation to maintain customer or supplier relationships, or promote employee management. 
Table 4. The influence of endogenous innovation on manufacturing firms' development

\begin{tabular}{|c|c|c|c|c|}
\hline Variables & $\boldsymbol{T} \boldsymbol{Q}_{i, t}$ & $\boldsymbol{T} \boldsymbol{Q}_{i, t+\mathbf{1}}$ & $\boldsymbol{T} \boldsymbol{Q}_{i, t+\mathbf{2}}$ & $\boldsymbol{T} \boldsymbol{Q}_{i, \boldsymbol{t}}$ \\
\hline$E I$ & $2.826^{*}$ & $3.181^{*}$ & $4.464^{* * *}$ & $-5.612^{* *}$ \\
\hline$E I^{2}$ & $(1.75)$ & $(1.83)$ & $(2.64)$ & $(-2.20)$ \\
\hline & & & & $10.97^{* * *}$ \\
\hline$S$ & $-0.483^{* * *}$ & $-0.395^{* * *}$ & $-0.298^{* * *}$ & $-1.050^{* * *}$ \\
\hline & $(-5.78)$ & $(-5.21)$ & $(-4.56)$ & $(-5.19)$ \\
\hline$R$ & 0.0721 & 0.0941 & 0.0832 & -0.0137 \\
\hline$L$ & $(1.12)$ & $(1.54)$ & $(1.42)$ & $(-0.27)$ \\
\hline & $-1.808^{* * *}$ & $-2.441^{* * *}$ & $-2.600^{* * *}$ & -0.742 \\
\hline$N$ & $(-3.79)$ & $(-4.82)$ & $(-4.96)$ & $(-1.62)$ \\
\hline & -0.161 & -0.246 & $-0.286^{*}$ & -0.204 \\
\hline Age & $(-1.04)$ & $(-1.60)$ & $(-1.92)$ & $(-1.32)$ \\
\hline & -0.0159 & -0.0161 & -0.0105 & 0.0425 \\
\hline Year & $(-1.29)$ & $(-1.35)$ & $(-0.91)$ & $(1.20)$ \\
\hline Constant & Yes & Yes & Yes & Yes \\
\hline & $14.34^{* * *}$ & $12.87^{* * *}$ & $10.67^{* * *}$ & $25.87^{* * *}$ \\
\hline$R^{2}$ & $(7.72)$ & $(7.74)$ & $(7.69)$ & $(6.23)$ \\
\hline Adj. $R^{2}$ & 0.276 & 0.273 & 0.239 & 0.108 \\
\hline Obs. & 0.273 & 0.270 & 0.236 & 0.105 \\
\hline
\end{tabular}

Note. The t-statistics are noted in parentheses; $* \mathrm{p}<0.10, * * \mathrm{p}<0.05$ and $* * * \mathrm{p}<0.01$.

Table 5. Threshold estimator $($ level $=95 \%)$

\begin{tabular}{|c|c|c|c|}
\hline Model & Threshold & Lower & Upper \\
\hline Th-1 & 0.0344 & 0.0303 & 0.0388 \\
\hline Th-21 & 0.0344 & 0.0259 & 0.0388 \\
\hline Th-22 & 0.0241 & 0.0216 & 0.0267 \\
\hline Th-3 & 0.0267 & 0.0216 & 0.0308 \\
\hline
\end{tabular}

Table 6. Threshold effect test (Bootstrap $=400400400)$

\begin{tabular}{|c|c|c|c|c|c|}
\hline Threshold & Fstat & Pro & Crit10 & Crit5 & Crit1 \\
\hline Single & 3.56 & 0.0775 & 2.9557 & 4.3507 & 14.5614 \\
\hline Double & 14.78 & 0.01 & 4.2743 & 7.1064 & 13.9759 \\
\hline Triple & 4.23 & 0.225 & 6.7062 & 10.3354 & 18.2103 \\
\hline
\end{tabular}

\section{AUTHORS' CONTRIBUTIONS}

Conceptualization, Shuxiang Wang; methodology, Jianjun Sun; software, Jianjun Sun and Fang Yuan; validation, Jianjun Sun and Shuxiang Wang; formal analysis, Jianjun Sun; resources, Jianjun Sun; data curation, Jianjun Sun and Fang Yuan; writing - original draft preparation, Jianjun Sun; writing-review and editing, Jianjun Sun, Shuxiang Wang and Fang Yuan; supervision, Shuxiang Wang; funding acquisition, Shuxiang Wang.

\section{ACKNOWLEDGMENTS}

This research was funded by the Social Science Research Project Supported by Beijing Jiaotong University (B19SK00790).

\section{REFERENCES}

[1] D. J. Teece, Explicating dynamic capabilities: The nature and microfoundations of (sustainable) enterprise performance, Strategic Management Journal, 28 (2007) 1319-1350. DOI: https:// $10.1002 /$ smj. 640

[2] J.G. March, Exploration and exploitation in organizational learning. Organization Science, 2(1991) 71-87. DOI: https:// 10.1287/orsc.2.1.71

[3] K.Lee, F.Malerba, Catch-up cycles and changes in industrial leadership: Windows of opportunity and responses of firms and countries in the evolution of sectoral systems. Research Policy, 46(2017) 338351. DOI: https:// 10.1016/j.respol.2016.09.006 
[4] L.Kim, Limitation to Innovation: The Dynamics of Korea's Technological Learning; Harvard Business Press: Harvard, MA, USA, 2007.

[5] C. Freeman, The economics of industrial innovation, Social Science Electronic Publishing, 7 (1997) 215-219.

[6] H. Chesbrough, Open Innovation: The New Imperative for Creating and Profiting From Technology; Harvard Business School Press: New York, NY, USA, 2003.

[7] I. Nonaka, A dynamic theory of organizational knowledge creation. Organization Science, 5(1994) 14-37. DOI: https:// 10.1287/orsc.5.1.14

[8] H. W.Volberda, F. A. J. Van den Bosch, O. R. , Mihalache, Advancing Management Innovation: Synthesizing Processes, Levels of Analysis, and
Change Agents. Organization Studies, 35(9) (2014) 1245-1264. DOI: https:// $10.1177 / 0170840614546155$

[9] H. Ashbaughskaife, D.W. Collins, W.R. Kinney, R. Lafond, The Effect of SOX Internal Control Deficiencies on Firm Risk and Cost of Equity. Journal of Accounting Research, 47(2009) 1-43. DOI: https:// 10.1111/j.1475-679X.2008.00315.x

[10]D.Stoel, W.A.Muhanna, It internal control weaknesses and firm performance: An organizational liability lens. International Journal of Accounting Information Systems, 12(2011) 280304. DOI: https:// 10.1016/j.accinf.2011.06.001

[11]B. E. Hansen, Threshold effects in non-dynamic panels: Estimation, testing, and inference. Journal of Econometrics, 93 (2) (1999) 345-368. DOI: https:// 10.1016/S0304-4076(99)00025-1 